\title{
Relationship between fear of falling and balance factors in healthy elderly women: A confirmatory analysis
}

António M. Monteiro, Pedro Forte, Joana Carvalho, Tiago M. Barbosa \& Jorge E. Morais

To cite this article: António M. Monteiro, Pedro Forte, Joana Carvalho, Tiago M. Barbosa \& Jorge E. Morais (2019): Relationship between fear of falling and balance factors in healthy elderly women: A confirmatory analysis, Journal of Women \& Aging, DOI: 10.1080/08952841.2019.1681244

To link to this article: https://doi.org/10.1080/08952841.2019.1681244

曲 Published online: 07 Dec 2019.

Submit your article to this journal

Q View related articles $₫$

View Crossmark data ¿ 


\title{
Relationship between fear of falling and balance factors in healthy elderly women: A confirmatory analysis
}

\begin{abstract}
António M. Monteiro ${ }^{a}$, Pedro Forte (1) a,b,c, Joana Carvalho ${ }^{d}$, Tiago M. Barbosa (1) ${ }^{a, b, e}$, and Jorge E. Morais (10) ${ }^{a, b}$

a Department of Sport Sciences, Instituto Politécnico de Bragança, Bragança, Portugal; ${ }^{\text {b}}$ Research Centre in Sports, Health and Human Development (CIDESD), University of Trás-os-Montes and Alto Douro, Vila Real, Portugal; 'Department of Sport Sciences and Physical Education, Higher Institute of Educational Sciences of the Douro, Penafiel, Portugal; dResearch Center in Physical Activity, Health and Leisure, University of Porto, Porto, Portugal; eNational Institute of Education, Nanyang Technological University, Singapore
\end{abstract}

\begin{abstract}
The aim of this study was to develop a confirmatory model, using structural equation modeling, to describe and explain the fear of falling in elderly women. Forty-one participants $(67.69 \pm 5.30$ years) were selected to test a theoretical model. The final model revealed that the fear of falling is related to impaired balance (dynamic and static). Strength has a positive effect on both dynamic and static balance. Strength depends on bone mineral density. In conclusion, more strength and bone mineral density and better body balance tend to decrease the fear of falling.
\end{abstract}

\section{KEYWORDS}

Balance; biomechanics; dynamic; static

\section{Introduction}

Falls in elderly people are an epidemic issue worldwide. More than one-third of the elderly population (i.e., more than 65 years old) fall each year (Joshua et al., 2014). It is reported that $10 \%$ to $20 \%$ of falls result in serious injuries such as fractures and traumas, leading to a morbidity state and/or to a reduction in life quality (Joshua et al., 2014; Kannus et al., 1999). In addition to that, treatment of these injuries are expensive, making this an important public issue (e.g., Stevens, Corso, Finkelstein, \& Miller, 2006).

This phenomenon seems to be more obvious in women than in men. The sex effect is related to changes in the hormonal response at some point of the life span and hence to a decrease in bone mineral density (BMD) (e.g., Fabricio, Rodrigues, \& Da Costa, 2004). Moreover, it was suggested that multitasking increases women's gait variability, and this has a direct relationship to the prevalence of falls (Johansson, Nordstrom, \& Nordstrom, 2016). This has a meaningful impact

CONTACT Jorge E. Morais morais.jorgestrela@gmail.com $\Theta$ Department of Sport Sciences, Polytechnic Institute of Bragança, Campus Sta. Apolónia, Apartado 1101, Bragança 5301-856, Portugal. 
on the quality of life of elderly people, since not only falls but also the fear of falling have effects on social and psychological behavior (Roe et al., 2008).

The literature reports that the etiology of falls is multifactorial (e.g., Rubenstein, 2006). This might be related to subjects' intrinsic factors (biological traits) such as genetics (e.g., Wheeler \& Kim, 2011) and/or extrinsic factors that are mainly related to balance and posture impairments (e.g., Dunsky, Zeev, \& Netz, 2017; Tinetti, Doucette, Claus, \& Marottoli, 1995) and muscle strength (e.g., Daley \& Spinks, 2000; Granacher \& Hortobágyi, 2015). For instance, Bergland and Wyller (2004) showed that elderly women presenting an abnormal balance while walking were more likely to fall. This balance issue in the frontal plane may explain the reasoning why a high percentage of falls occur to the side (Nevitt \& Cumming, 1993). Moreover, these balance and posture impairments might be related to lower limb strength. Studies have reported that a decrease in lower limb strength is associated with a higher risk of falling (Cho, Bok, Kim, \& Hwang, 2012; Skelton, Kennedy, \& Ruthford, 2002).

However, such assumptions are based on exploratory research, where the aim was to identify the variables that are related to falls. Confirmatory research aims to verify if such phenomena really happen or not (Morais et al., 2012). It seems that the employment of confirmatory models reporting the links between the risk of fall determinant factors has never been carried out before. Such a model can be useful to have a deeper insight into the relationships between these determinant factors and how they play a role in the fear of falling. Moreover, the existent literature's body of knowledge may be incompletely informed due to lack of confirmatory models. Thus, practitioners might be able to design customized intervention programs to tackle such fear. Indeed, only one study can be found about confirmatory analysis of latent variables using factor analysis, including concern about falls, medication use, and impairments in daily activities (Noureldin, Hass, Abrahamson, \& Arling, 2018).

The aim of this study was to develop a confirmatory model, by structural equation modeling, to describe and explain the fear of falling of elderly women based on bone mineral density, muscle strength, and dynamic and static balance. It was hypothesized that bone mineral density would have a direct effect on dynamic balance and lower limb strength on static balance. Both static and dynamic balance would significantly explain the fear of falling by elderly people.

\section{Materials and methods}

The sample was composed of 41 women aged between 60 and 85 years old (age: $67.69 \pm 5.30$ years old; height: $1.55 \pm 0.08 \mathrm{~m}$; body mass: $72.44 \pm 14.52 \mathrm{~kg}$; body mass index: $\left.30.05 \pm 5.65 \mathrm{~kg} \cdot \mathrm{m}^{-2}\right)$. Inclusion criteria were as follows: (a) women, (b) over 60 years old, and (c) functionally independent. Exclusion criteria included diagnosis of diseases, conditions, 
or illness that might affect the experimental protocol. All participants gave informed consent/assent for participation in this study, and all procedures were in accordance with the Helsinki Declaration in respect to human research. The Ethics Board approved the study design.

\section{Bone mineral density}

Bone mineral density (BMD, in standard deviation) was chosen as an indicator of risk factor. The major role of this procedure includes the diagnosis of osteoporosis and the assessment of risk of fracture (Blake \& Fogelman, 2007). The BMD was assessed after full-body scans by dual x-ray absorptiometry equipment (Hologic, QDR-4500, Bedford, MA, USA). Standardized procedures with the subjects in a prone position were carried out (Heymsfield et al., 1990). The T-score was selected as variable.

\section{Strength data collection}

Knee torque ( Isok $_{\text {strength }}$, in $\mathrm{N} \cdot \mathrm{m}^{-1}$ ) was selected as the lower limb strength outcome, since it evaluates the function as well as the strength of a joint. Before the strength measurements, a standard warm-up was performed on a cyclo-ergometer (Monark, Sweden) for 5 minutes at $60 \mathrm{rpm}$, with an external load of $2 \%$ of the body weight. Knee extensor strength of the dominant limb was evaluated on an isokinetic dynamometer (Biodex System 2, Shirley, NY, USA) for $60^{\circ}$ seconds during three maximal repetitions (Melzer, Benjuya, \& Kaplanski, 2004). The knee's maximal peak torque was measured. To ensure full recovery, a minimum rest period of 15 minutes was given between repetitions. The best repetition was used for further analysis.

\section{Dynamic balance}

Dynamic balance was evaluated with the "Time-Up-\&-Go" functional test (in s)during $2.44 \mathrm{~m}$ (Rikli \& Jones, 1999). The test consists of getting up from a chair, walking $2.44 \mathrm{~m}$, turning around, and getting back to the starting point and is commonly used to assess elderly dynamic balance (e.g., Bergland \& Wyller, 2004). A video camera (Sony FDR-x3000, Toquio, Japan) was used in the sagittal plane to capture the start and finish. Time needed to complete the test was measured with video analysis software (Kinovea, v0.8.15). Each subject performed three trials, and the best time was used for further analysis. 


\section{Static balance}

Vertical projection of the body's center of mass (CoM, in \%) in the base of support was assessed by photogrammetry with dedicated software (PAS/SAPO) (Ferreira, Duarte, Maldonado, Burke, \& Marques, 2010). This is a feasible, noninvasive, nonexpensive, and valid procedure to assess static postures. Subjects were barefoot and minimally dressed to allow the visualization of 32 anatomic landmarks, where markers with $15 \mathrm{~mm}$ circumference were placed. Digital photos of the front, back, left, and right views were shot (Sony, Cibershot, 12.1MP, Tokyo, Japan) during quiet standing. The CoM's location was assessed with dedicated software (SAPo, v. 0.68, University of São Paulo, Brazil). After manual digitalization of all anatomical landmarks, in the four views, 2D CoM location was calculated by the segmentation method:

$$
\mathrm{X}_{\mathrm{CoM}}=\frac{\sum_{i=1}^{n} x_{i} \cdot m_{i}}{\sum_{i=1}^{n} m_{i}}
$$

and,

$$
\mathrm{Y}_{\mathrm{CoM}}=\frac{\sum_{i=1}^{n} y_{i} \cdot m_{i}}{\sum_{i=1}^{n} m_{i}}
$$

where $\mathrm{X}_{\mathrm{CoM}}$ and $\mathrm{Y}_{\mathrm{CoM}}$ are the coordinates of the body's overall CoM, $\mathrm{x}_{\mathrm{i}}$ and $y_{i}$ are the coordinates of the limbs' partial CoM, and $m_{i}$ the limbs' partial masses reported elsewhere (Zatsiorsky \& Seluyanov, 1983). Vertical projection of the CoM asymmetry in sagittal and frontal planes were calculated, considering the interception of both planes as the origin of a Cartesian system. The CoM position coordinates was set as:

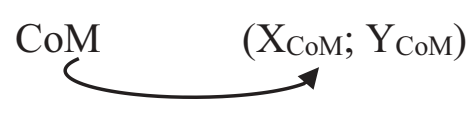

where CoM is the center of mass, $\mathrm{X}_{\mathrm{CoM}}$ the asymmetry in the sagittal plane (i.e., horizontal position vector of the gravity line in the base of support), and $\mathrm{Y}_{\mathrm{CoM}}$ the asymmetry in the frontal plane (i.e., lateral position vector of the gravity line in the base of support). Thereafter the resultant vector $\left(\mathrm{R}_{\mathrm{CoM}}\right)$ of the $\mathrm{X}_{\mathrm{CoM}}$ and $\mathrm{Y}_{\mathrm{CoM}}$ with application points in the origin of the Cartesian system was calculated: 


$$
\mathrm{R}_{\mathrm{CoM}}=\sqrt{\left(\frac{\sum_{i=1}^{n} x_{i} \cdot m_{i}}{\sum_{i=1}^{n} m_{i}}\right)^{2}+\left(\frac{\sum_{i=1}^{n} y_{i} \cdot m_{i}}{\sum_{i=1}^{n} m_{i}}\right)^{2}}
$$

where $\mathrm{R}_{\mathrm{CoM}}$ is the resultant vector, $\mathrm{X}_{\mathrm{CoM}}$ and $\mathrm{Y}_{\mathrm{CoM}}$ are the coordinates of the body's vertical projection of the CoM, $\mathrm{x}_{\mathrm{i}}$ and $\mathrm{y}_{\mathrm{i}}$ are the coordinates of the limbs' partial CoM, and $m_{i}$ the limbs' masses. So the higher the $\mathrm{R}_{\mathrm{CoM}}$ value, the more distant the vertical projection of the CoM from the origin of the Cartesian system and therefore closer from the limits of the base of support. Hence, the closer $\mathrm{R}_{\mathrm{CoM}}$ is from the limits of support, the poorer the static balance.

\section{Falls}

For the assessment of falls/fear of falling, the Falls Efficacy Scale (FES, in a.u.) was used (Tinetti, Richman \& Powell, 1990). This is a often-used clinical balance assessment tool due to its inclusion of both balance and gait and also its reliability and sensitivity. The final score (minimum 10, maximum 100) is the sum of 10 items that assess the confidence to carry out some daily routines (e.g., reaching an object, waking at home, etc.) in a 10-point Likert scale.

\section{Theoretical model}

The theoretical model (Figure 1) was designed based on exploratory research, where lower limb strength and BMD are associated with balance (Cho et al., 2012; Greenspan et al., 1998).

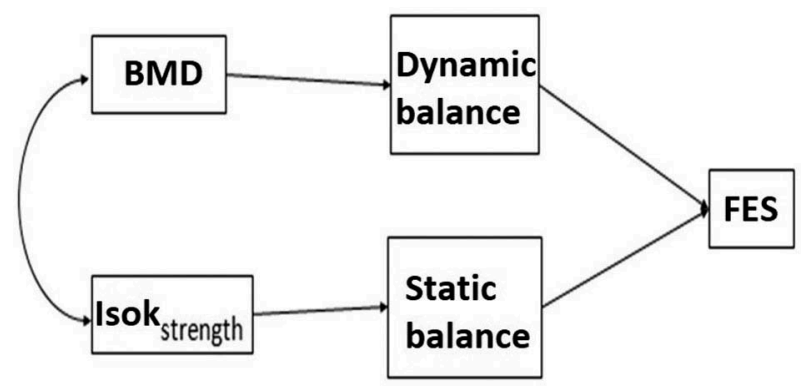

Figure 1. Theoretical model to be tested. BMD (bone mineral density); Isok strength $_{\text {(knee exten- }}$ sors' strength); FES (Falls Efficacy Scale); $\beta x_{i}, y_{i}$ (beta value for regression model between variables); $E_{x i}$ (disturbance term for a given variable [residual error]); $x_{i} \leftrightarrow y_{i}$ (variables $x_{i}$ and $y_{i}$ are correlated); $x_{i} \rightarrow y_{i}$ (variable $y_{i}$ depends on variable $x_{i}$ ). 
The FES was selected as the dependent parameter (variable being predicted). Remaining parameters were selected as independent (variables responsible for the prediction). It was considered that there is a covariance between BMD and Isok $_{\text {strength }}$. BMD would have a direct effect on dynamic balance and an indirect one on static balance, with muscle strength parameter ( Isok $_{\text {strength }}$ ) as mediator. Isok $_{\text {strength }}$ would have a direct effect on static balance and an indirect one on dynamic balance, with BMD as mediator. Both static and dynamic balance would have a direct effect on falls/fear of falling (FES).

\section{Statistical procedures}

Descriptive statistics (mean \pm 1 standard deviation, minimum, and maximum) with 95\% confidence interval (95CI) from all variables were calculated. Pearson correlation coefficients were computed between all variables $(P \leq .05)$.

For the structural equation modeling (confirmatory analysis) the path-flow method was used. The interpretation of this kind of approach is based on: (a) the variables included (inserted inside squares); (b) the links (i.e., an arrow between two variables represent that one variable determines the other); (c) beta values (i.e., contribution of one variable to the other: When the origin variable increases by one unit the destination variable increases by the amount of the beta value); and (d) residual errors and/or determination coefficient (represents the variable predictive error or the variable predictive value respectively) (Morais et al., 2012). The theoretical model was tested, and a confirmatory model was obtained (i.e., a model that verified and confirmed the theoretical one).

Path-flow analysis was performed with the estimation of linear regression standardized coefficients between the dependent and independent variables. All assumptions to perform the path-flow analysis were considered. When appropriate, according to the theoretical model, simple or multiple linear regression analysis was computed. Standardized regression coefficients $(\beta)$ were considered (Barbosa et al., 2010). The effect size of the disturbance term, reflecting unmeasured variables, for a given endogenous variable, was $1-\mathrm{R}^{2}$. Significance of each $\beta$ was assessed with the Student's $t$-test $(P \leq .05)$. To measure the model's goodness-of-fit, the standardized root mean square residuals (SRMR) was calculated:

$$
S R M R=\sqrt{\frac{\sum_{i=1}^{p} \sum_{i=1}^{q}(r i j-p i j)^{2}}{p+q}}
$$

where $r$ is the Pearson correlation coefficients and $p$ the correlation predicted by the model (based on total effect, i.e., the addiction of the direct and 
Table 1. Descriptive statistics of the variables selected with $95 \%$ confidence interval $(95 \mathrm{Cl})$ and the Pearson correlation between the dependent variable (FES) and remaining independent variables.

\begin{tabular}{lcccrrr}
\hline & & & & & \multicolumn{2}{c}{ Pearson correlation } \\
\cline { 3 - 7 } & Mean $\pm 1 S D$ & Min & Max & $95 \mathrm{Cl}$ & $\mathrm{r}$ & $\mathrm{p}$ \\
\hline BMD [SD] & $-0.76 \pm 1.14$ & -3.20 & 3.10 & $(-1.47 ; 2,99)$ & 0.24 & 0.06 \\
Isok $_{\text {strength }}\left[\mathrm{N} \cdot \mathrm{m}^{-1}\right.$ ] & $102.86 \pm 25.72$ & 55.40 & 182.60 & $(52.45 ; 153.27)$ & -0.30 & 0.02 \\
Static balance [\%] & $27.07 \pm 10.52$ & 10.48 & 60.40 & $(6.45 ; 47.69)$ & -0.31 & 0.02 \\
Dynamic balance [s] & $4.74 \pm 0.84$ & 3.40 & 8.00 & $(3.09 ; 6.39)$ & -0.01 & 0.96 \\
FES [a.u.] & $88.57 \pm 8.74$ & 66 & 100 & $(71.44 ; 105.70)$ & & \\
\hline
\end{tabular}

Note. $\mathrm{BMD}=$ bone mineral density; Isok $_{\text {strength }}=$ isokinetic strength (knee); FES = Falls Efficacy Scale.

indirect effects plus spurious effects). The SRMR measures the standardized difference between the observed covariance and predicted covariance. It is considered a rule of thumb that if: (a) SRMR $<0.1$ that the model adjusts to the theory; (b) SRMR $<0.05$ that the model adjusts very well to the theory; and (c) SRMR $\sim 0$ that the model is perfect (Barbosa et al., 2010).

\section{Results}

Data dispersion, expressed as one standard deviation (1SD), and range was moderate-high for most variables (Table 1). This was especially obvious in BMD $(-3.20 \leq \mathrm{BMD} \leq 3.10 \mathrm{SD})$, Isok $_{\text {strength }}\left(55.40 \leq \mathrm{Isok}_{\text {strength }} \leq 182.60 \mathrm{~N} \cdot \mathrm{m}^{-1}\right)$, static balance (10.48 $\leq$ static balance $\leq 60.40 \%)$, and dynamic balance $(3.40 \leq$ dynamic balance $\leq 8.00 \mathrm{~s})$.

The FES noted a significant correlation with $\operatorname{Isok}_{\text {strength }}(r=-0.30$, $P=.02)$ and static balance $(r=-0.31, P=.02)$ (Table 1$)$. The testing of the theoretical model was done in two steps (Figure 2). Firstly, nonsignificant paths (BMD to dynamic balance: $\beta=-0.02, P>.05$ ) were identified (Figure 2a). And in this first step, the model's goodness-of-fit (Figure 2a) was unacceptable (SRMR > 1.0). Thereafter, the model was run once again, but this time after removing the nonsignificant link (Figure 2b). Upon that and recomputation of the data, the new confirmatory model increased the goodness-of-fit to acceptable values, i.e., the model adjusts to the theory (Figure $2 \mathrm{~b}$; SRMS $=0.08$ ). The highest direct effect was noted between the static balance and the FES $(\beta=-0.46, P<.001)$. This means that an increase by 1 unit in static balance would lead to a 0.46 decrease in the FES (i.e., a higher static balance contributes to a lower fall/fear of falling).

\section{Discussion}

The aim of this study was to design and run a confirmatory model describing and explaining the fear of falling in elderly women based on BMD, strength 

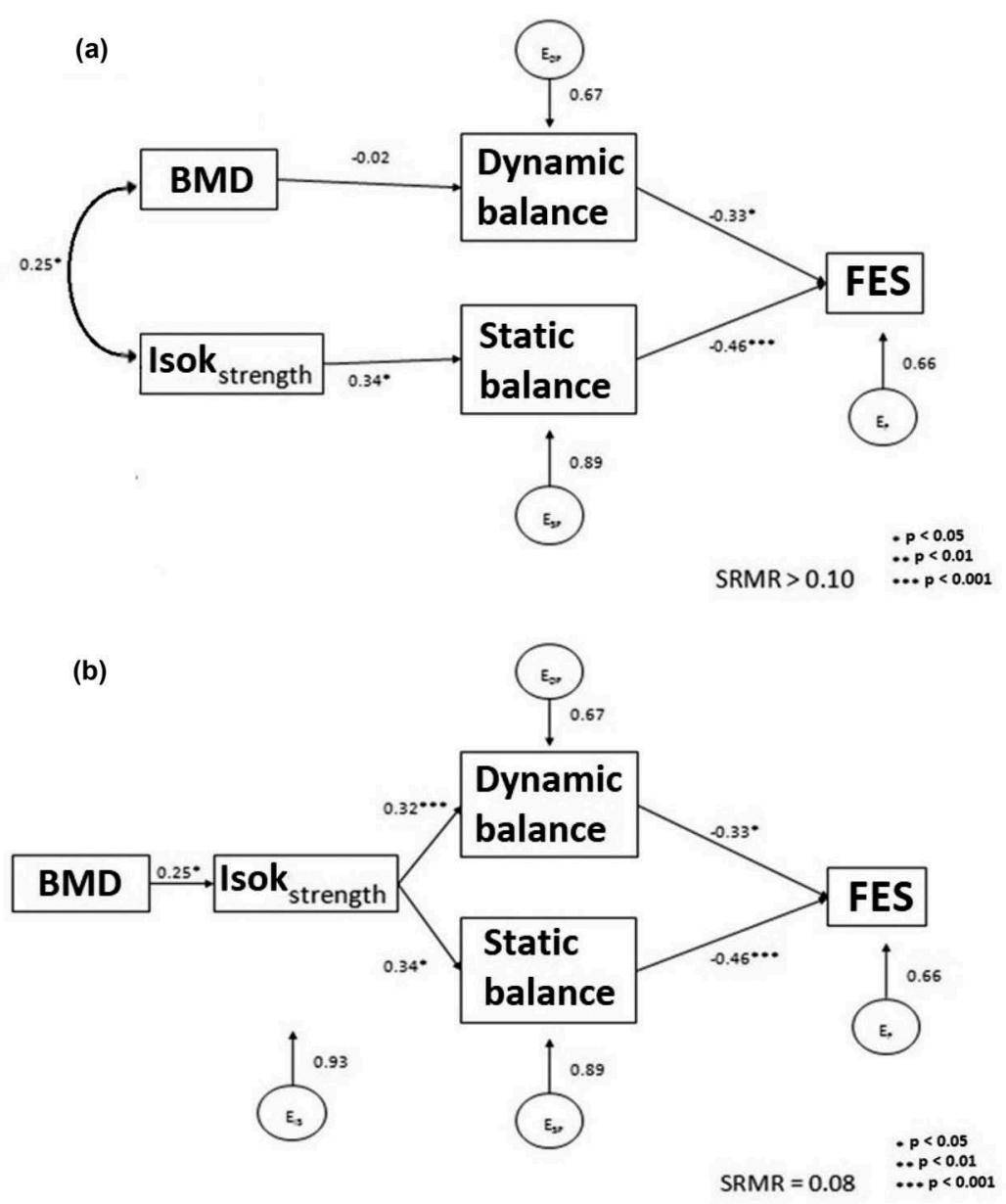

Figure 2. Confirmatory path-flow model including all variables computed (2a) and deleting nonsignificant links, with the subsequent recomputation of the model (2b). BMD (bone mineral density); Isok strength (knee extensors' strength); FES (Falls Efficacy Scale); SRMR (standardized root mean square residual); $\beta x_{i} y_{i}$ (beta value for regression model between variables); $E_{x i}$ (disturbance term for a given variable [residual error]); $x_{i} \leftrightarrow y_{i}$ (variables $x_{i}$ and $y_{i}$ are correlated); $x_{i} \rightarrow y_{i}$ (variable $y_{i}$ depends from variable $x_{i}$ ).

( Isok $\left._{\text {strength }}\right)$, and dynamic and static balance. Overall, it might be suggested that BMD has a direct effect on strength ( $\left(\mathrm{Isok}_{\mathrm{strength}}\right)$ and strength on dynamic and static balance. It is noteworthy that static balance presented a higher direct effect to falls/fear of falling than did dynamic balance.

Overall, this sample is composed of women who present better results than the cutoff values suggested in literature (e.g., Shumway-Cook, Brauer, \& Woollacott, 2000; Tinetti, Richman, \& Powell, 1990). It was recently reported that physical activity levels do have a positive effect on falls or risk of falls in elderly people (Duray \& Genç, 2017). So it might be considered that the amount of physical activity plays a major role in falls in the elderly. Regarding the exploratory 
statistical approach, present data revealed mixed findings in comparison to the literature. For instance, dynamic balance, measured by the "Time-Up-\&-Go" functional test, and BMD presented a nonsignificant correlation with the FES (Table 1). The literature reported that dynamic balance had a positive relationship with fear of falling (e.g., Bergland \& Wyller, 2004; Duray \& Genç, 2017). Furthermore, BMD presented a significant relationship with level of physical activity and hence a lower risk of falling (Amiri, Hosseini, Rahmaninia, Nooreddini, \& Bijani, 2015). Isok $k_{\text {strength }}$ and static balance did present a significant correlation with the FES. Studies showed that elderly people who are more likely to fall presented less lower-limb strength (Cho et al., 2012; Melzer \& Oddsson, 2012). Better static balance was also noted in elderly people who didn't fall or who fell less frequently. More strength and better static balance are associated with a lower fear of falling. Indeed, it is reported in the literature that more strength is related to better balance (Skelton, 2001) and better balance to less fear of falling (Cao, Maeda, Shima, Kurata, \& Nishizono, 2007; Maki et al., 2008).

In the theoretical model, and consequently the first confirmatory model computed (Figure 2a), a nonsignificant direct effect was observed between BMD and dynamic balance $(\beta=-0.02, P>.05)$. This link was hypothesized because it was suggested that osteoporotic patients have balance impairments walking, leading to a higher risk of falling (Radaei \& Gharibzadeh, 2013). However, a significant direct effect between these two variables did not happen. Hence, a model with a new path design was recomputed, with all links then denoted significant paths (Figure 2b). In the first level, a path between BMD and Isok $_{\text {strength }}$ was linked. It was reported that an increase in BMD is related to more strength and that only muscle-skeletal systems with higher BMD can be submitted to higher mechanical loads (e.g., Hyakutake, Goto, Yamagata, \& Moriya, 1994; Kohrt, Bloomfield, Little, Nelson, \& Yingling, 2004). On a second level of the model, strength had a positive and significant effect on both dynamic $(\beta=0.32, P<.001)$ and static balance $(\beta=0.34, P<.05)$. This means that an

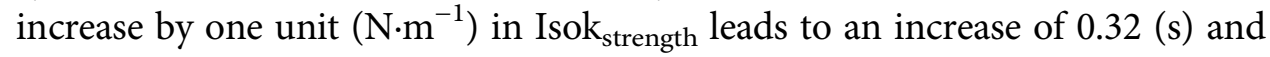
0.34 (\%) units in dynamic and static balances respectively (Figure 2b). Studies aiming to understand the relationship between lower limb strength and balance (dynamic and static) reported that despite verified associations, the neuromuscular components associated with dynamic and static balance are different (Melzer \& Oddsson, 2012; Muehlbauer, Gollhofer, \& Granacher, 2015). Nevertheless, the present data showed a significant direct effect of lower limb strength on both types of balance. Lastly, the final level revealed that falls/fear of falling is related to impaired balance (dynamic and static). Higher values of dynamic and static balance significantly decrease falls/fear of falling (FES). Nevertheless, static balance did show a higher and significant direct effect on the FES $(\beta=-0.46, P<.001)$ in comparison with dynamic balance $(\beta=-0.33$, $P<.01)$. A study conducted by Razavi (2017) reported that increasing the sway angle (in static balance) increased the participants' base of support, indicating 
a better postural sway. Conversely, for dynamic balance, an increase in the sway angle indicated a "chaos" in the center of gravity vertical projection. This suggested that it took more effort to maintain participants' stability during dynamic balance. Moreover, it was observed that frail elderly people presented significant differences in static balance in comparison to healthy counterparts, but not in dynamic balance (Fujita et al., 2015). Altogether, this suggests that the major determinant for a hypothetical fall or risk of falling might be static balance.

Therefore, all this conceptualization should be explored in the future to have a better insight of this model's links. It would be of extreme importance to understand and confirm which type of balance is mainly responsible for falls in the elderly and the parameters that better determine each one (i.e., static and dynamic balance). This would provide key information about how to prevent falls in the elderly population. A main limitation of this study could be that static posture is measured by body sway.

\section{Conclusions}

As a conclusion, a model to explain the fear of falling based on BMD, strength ( Isok $_{\text {strength }}$ ), and static and dynamic balance was obtained. More strength and BMD and better body balance tend to decrease the fear of falling. Nevertheless, static balance did highly contribute to the fear of falling (i.e., the higher static balance, the less fear of falling).

\section{Disclosure statement}

No potential conflict of interest was reported by the authors.

\section{Funding}

This work was supported by the Portuguese Foundation for Science and Technology, I.P. (Fundação para a Ciência e a Tecnologia) under project UID/DTP/04045/2019.

\section{ORCID}

Pedro Forte (10) http://orcid.org/0000-0003-0184-6780

Tiago M. Barbosa (i) http://orcid.org/0000-0001-7071-2116

Jorge E. Morais (D) http://orcid.org/0000-0002-6885-0648

\section{References}

Amiri, A., Hosseini, S. R., Rahmaninia, F., Nooreddini, H., \& Bijani, A. (2015). Relationship between bone mineral density and physical activity level in the elderly. Annals of Applied Sport Science, 3(2), 23-32. doi:10.18869/acadpub.aassjournal.3.2.23 
Barbosa, T. M., Costa, M. J., Marinho, D. A., Coelho, J., Moreira, M., \& Silva, A. J. (2010). Modeling the links between young swimmers' performance: Energetic and biomechanic profiles. Pediatric Exercise Science, 22(3), 379-391.

Bergland, A., \& Wyller, T. B. (2004). Risk factors for serious fall related injury in elderly women living at home. Injury Prevention, 10(5), 308-310. doi:10.1136/ip.2003.004721

Blake, G. M., \& Fogelman, I. (2007). The role of DXA bone density scans in the diagnosis and treatment of osteoporosis. Postgrad Medicine Journal, 83, 509-517. doi:10.1136/ pgmj.2007.057505

Cao, Z. B., Maeda, A., Shima, N., Kurata, H., \& Nishizono, H. (2007). The effect of a 12-week combined exercise intervention program on physical performance and gait kinematics in community-dwelling elderly women. Journal of Physiological Anthropology, 26, 325-332.

Cho, K. H., Bok, S. K., Kim, Y., \& Hwang, S. L. (2012). Effect of lower limb strength on falls and balance of elderly. Annual Rehabilitation Medicine, 36, 386-393. doi:10.5535/ arm.2012.36.3.386

Daley, M. J., \& Spinks, W. L. (2000). Exercise, mobility and aging. Sports Medicine, 29, 1-12. doi:10.2165/00007256-200029010-00001

Dunsky, A., Zeev, A., \& Netz, Y. (2017). Balance performance is task specific in older adults. Biomed Research International, 7. Retrieved from https://doi.org/10.1155/2017/6987017.

Duray, M., \& Genç, A. (2017). The relationship between physical fitness and falling risk and fear of falling in community-dwelling elderly people with different physical activity levels. Turkish Journal of Medicine Science, 47(2), 455-462. doi:10.3906/sag-1511-101

Fabricio, S. C., Rodrigues, R. A., \& Da Costa, M. L. (2004). Falls among older adults seen at a Sao Paulo State public hospital: Causes and consequences. Public Health Journal, 38, 93-99.

Ferreira, E. A., Duarte, M., Maldonado, E. P., Burke, T. N., \& Marques, A. P. (2010). Postural assessment software (PAS/SAPO): Validation and reliability. Clinics, 65, 675-681. doi:10.1590/S1807-59322010000700005

Fujita, E., Takeshima, N., Hasegawa, T., Narita, M., Kato, Y., Koizumi, D., \& Rogers, M. E. (2015). Comparison of static and dynamic balance in healthy but untrained versus frail community-dwelling older adults. Physical Medicine and Rehabilitation International, 2(5), 1046.

Granacher, U., \& Hortobágyi, T. (2015). Exercise to improve mobility in healthy aging. Sports Medicine, 45(12), 1625-1626. doi:10.1007/s40279-015-0405-9

Greenspan, S. L., Myers, E. R., Kiel, D. P., Parker, R. A., Hayes, W. C., \& Resnick, N. M. (1998). Fall direction, bone mineral density, and function: Risk factors for hip fracture in frail nursing home elderly. American Journal of Medicine, 104(6), 539-545. doi:10.1016/ s0002-9343(98)00115-6

Heymsfield, S. B., Smith, R., Aulet, M., Bensen, B., Lichtman, S., Wang, J., \& Pierson, R. N. (1990). Appendicular skeletal muscle mass: Measurement by dual-photon absorptiometry. American Journal of Clinical Nutrition, 52, 214-218. doi:10.1093/ajcn/52.2.214

Hyakutake, S., Goto, S., Yamagata, M., \& Moriya, H. (1994). Relationship between bone mineral density of the proximal femur and lumbar spine and quadriceps and hamstrings torque in healthy Japanese subjects. Calcified Tissue International, 55(3), 223-229. doi:10.1007/bf00425879

Johansson, J., Nordstrom, A., \& Nordstrom, P. (2016). Greater fall risk in elderly women than in men is associated with increased gait variability during multitasking. Journal of the American Medical Directors Association, 17(6), 535-540. doi:10.1016/j.jamda.2016.02.009

Joshua, A., D’Souza, V., Unikrishnan, B., Mithra, P., Kamath, A., Acharya, V., \& Venugopal, A. (2014). Effectiveness of progressive resistance strength versus traditional balance exercise in improving balance among the elderly - A randomised controlled trial. Journal of Clinical and Diagnostic Research, 8(3), 9-102. 
Kannus, P., Parkkari, J., Koskinen, S., Niemi, S., Palvanen, M., Jarvinen, M., \& Vuori, I. (1999). Fall-induced injuries and deaths among older adults. JAMA, 281(20), 1895-1899. doi:10.1001/jama.281.20.1895

Kohrt, W. M., Bloomfield, S. A., Little, K. D., Nelson, M. E., \& Yingling, V. R. (2004). American college of sports medicine position stand: Physical activity and bone health. Medicine and Science in Sports Exercise, 36, 1985-1996. doi:10.1249/01.MSS.0000142662.21767.58

Maki, B. E., Cheng, K. C., Mansfield, A., Scovil, C. Y., Perry, S. D., Peters, A. L., ... Mcllroy, W. E. (2008). Preventing falls in older adults: New interventions to promote more effective change-in-support balance reactions. Journal of Electromyography Kinesiology, 18, 243-254. doi:10.1016/j.jelekin.2007.06.005

Melzer, I., Benjuya, N., \& Kaplanski, J. (2004). Postural stability in the elderly: A comparison between fallers and non-fallers. Age \& Ageing, 33, 602-607. doi:10.1093/ageing/afh218

Melzer, I., \& Oddsson, L. (2012). Improving balance control and self-reported lower extremity function in community-dwelling older adults: A randomized trial. Clinical Rehabilitation, 27(3), 195-206. doi:10.1177/0269215512450295

Morais, J. E., Jesus, S., Lopes, V., Garrido, N. D., Silva, A. J., Marinho, D. A., \& Barbosa, T. M. (2012). Linking selected kinematic, anthropometric and hydrodynamic variables to young swimmer performance. Pediatric Exercicise Science, 24(4), 649-664. doi:10.1123/ pes.24.4.649

Muehlbauer, T., Gollhofer, A., \& Granacher, U. (2015). Associations between measures of balance and lower-extremity muscle strength/power in healthy individuals across the lifespan: A systematic review and meta-analysis. Sports Medicine, 45(12), 1671-1692. doi:10.1007/s40279-015-0390-Z

Nevitt, M. C., \& Cumming, S. R. (1993). Type of fall and risk of hip and wrist fractures: The study of osteoporotic fractures. The study of osteoporotic fractures research group. Journal of American Geriatric Society, 41, 1226-1234. doi:10.1111/j.1532-5415.1993.tb07307.x

Noureldin, M., Hass, Z., Abrahamson, K., \& Arling, G. (2018). Fall risk, supports and services, and falls following a nursing home discharge. Gerontologist, 58(6), 1075-1084. doi:10.1093/geront/gnx133

Radaei, F., \& Gharibzadeh, S. (2013). Relationship between bone mineral density and balance disorders in osteoporotic patients. Frontiers Bioengineering and Biotechnology, 1(5). doi:10.3389/fbioe.2013.00005

Razavi, H. (2017). A comparison between static and dynamic stability in postural sway and fall risks. Journal of Ergonomics, 7(1), 1000186.

Rikli, R. E., \& Jones, C. J. (1999). Development and validation of a functional fitness test for community-residing older adults. Journal of Aging and Physical Activity, 7, 129-161. doi:10.1123/japa.7.2.129

Roe, B., Howell, F., Riniotis, K., Beech, R., Crome, P., \& Ong, B. N. (2008). Older people's experience of falls: Understanding, interpretation and autonomy. Journal of Advancing Nursing, 63, 586-596. doi:10.1111/j.1365-2648.2008.04735.x

Rubenstein, L. Z. (2006). Falls in older people: Epidemiology, risk factors and strategies for prevention. Age and Ageing, 35(2), 37-41. doi:10.1093/ageing/afj018

Shumway-Cook, A., Brauer, S., \& Woollacott, M. (2000). Predicting the probability for falls in community-dwelling older adults using the timed up \& go test. Physical Therapy, 80, 896-903.

Skelton, D. A. (2001). Effects of physical activity on postural stability. Age and Ageing, 30(4), 33-39. doi:10.1093/ageing/30.suppl_4.33

Skelton, D. A., Kennedy, J., \& Ruthford, O. M. (2002). Explosive power and asymmetry in leg muscle function in frequent fallers and non-fallers aged over 65. Age and Ageing, 31, 119-125. doi:10.1093/ageing/31.2.119 
Stevens, J., Corso, P., Finkelstein, E., \& Miller, T. (2006). The cost of fatal and non-fatal falls among older adults. Injury Prevention, 12(1), 290-295. doi:10.1136/ip.2005.011015

Tinetti, M. E., Doucette, J., Claus, E., \& Marottoli, R. (1995). Risk factors for serious injury during falls by older persons in the community. Journal of American Geriatric Society, 43, 1214-1221. doi:10.1111/j.1532-5415.1995.tb07396.x

Tinetti, M. E., Richman, D., \& Powell, L. (1990). Falls efficacy as a measure of fear of falling. Journal of Gerontology, 45, 239-243. doi:10.1093/geronj/45.6.P239

Wheeler, H. E., \& Kim, S. K. (2011). Genetics and genomics of human ageing. Philosophical Transactions of the Royal Society B, 366, 43-50. doi:10.1098/rstb.2010.0259

Zatsiorsky, V., \& Seluyanov, V. (1983). The mass and inertia characteristics of the main segments of the human body. In H. Matsui, \& K. Kobayashi (Eds.), Biomechanics VIII-B (pp. 1152-1159). Champaign, IL: Human Kinetics. 